\title{
LA VIDA COMO OBRA DE ARTE EN LA AUTOFICCIÓN DE ERNESTO SÁBATO
}

\author{
LIFE AS A WORK OF ART \\ IN THE AUTOFICTION OF ERNESTO SÁBATO
}

\section{Ronald GARCÍA GALLEGO}

Universidad del Valle

ronald.garcia.g@correounivalle.edu.co

\begin{abstract}
Resumen: La autoficción se define como la relación ambigua que existe entre autobiografía y ficción. Mi propósito, al analizar la autoficción en Abaddón, El Exterminador de Ernesto Sábato, es revelar cómo la conformación de la subjetividad de éste, por medio de la escritura, nos advierte de una comunicación subjetiva con el lector, pues es en ella donde la identidad del "autor" (tan refutada) es legitimada. Los puntos fundamentales son la autoficción y la metaficción en la obra. Acá, la representación, la referencialidad y la autorreferencialidad del autor son esenciales para explorar los procesos de subjetivación contemporáneos de esta sociedad mass-mediática.
\end{abstract}

Palabras clave: Autoficción. Autobiografía. Metaficción. Autorreferencialidad. Ernesto Sábato. Abaddón, El Exterminador.

Abstract: The autofiction is defined as the ambiguous relationship between autobiography and fiction. The purpose in analyzing the autofiction in Abaddón, El Exterminador of Ernesto Sábato, is to reveal how the 
conformation of the subjectivity of this, through writing, warns us of a subjective communication with the reader, because it is here where the identity of the "author" (so often refuted) is legitimated. The main points are the autofiction and metafiction in the work. In these, the representation, referentiality and self-referentiality of the author are essential to explore the debate related with the processes of contemporary subjectivation of this mass-mediatic society.

Key Words: Autofiction. Autobiography. Metafiction. Self-referentiality. Ernesto Sábato. Abaddón, El Exterminador.

\section{SOBRE AUTOFICCIÓN}

Pero, ¿es posible hablar de autoficción hispanoamericana, como lo es, por ejemplo, en otras literaturas? Ciertamente existe un tipo de novela similar o equivalente al que Jacques Lecarme ha censado en la literatura francesa, parecido a las "factual fictions" anglosajonas analizadas por Stone (1982) o a las [auto]novelas españolas.

¿Existe la autoficción Hispanoamericana? Manuel Alberca

Nada extraño resulta que la autoficción, como una manifestación de la escritura contemporánea, haya sido escasamente explorada por la teoría literaria en nuestro continente. Esto se debe, en gran parte, a que los debates que impulsan los grandes estudiosos de Europa y Norte América tardan un tiempo en manifestarse en nuestro ámbito. Por lo tanto, no es raro que este fenómeno nos parezca una artimaña de los escritores por confundir aún más la difusa brecha que existe entre la realidad y la ficción. Sin embargo, el panorama no es desalentador. Desde España, teóricos como Francisco Puertas Moya (2003), Manuel Alberca (2005), Alicia Molero de la Iglesia (2006), Vera Toro, Sabine Schlickers y Ana Luengo (2010), Ana Casas 
(2014) ${ }^{1}$, al igual que Julia Musitano (2010) en Argentina o Julia Erika Negrete Sandoval (2013) en México, se han interesado por este fenómeno en la escritura latinoamericana ${ }^{2}$.

La pregunta fundamental que nos hacemos al escuchar el término es ¿qué es una autoficción? A grandes rasgos, se puede decir que es un texto híbrido (y ¿qué no lo es en esta contemporaneidad?) que resulta de la ficcionalización de los hechos de la vida de un autor. No obstante, el asunto no es tan simple como la búsqueda de aspectos biográficos de un autor en sus obras. No. En primer lugar, se debe tener en cuenta que la autoficción es una voluntad del escritor por confundir y recrear su vida en el entramado narrativo. Sin esta voluntad autorreferencial sería muy simple adjudicar a los personajes de un autor sus propios rasgos, pues ¿no son en últimas sus creaciones? La cuestión está, entonces, en su propia auto-creación y no en la creación de otros "yo".

Puesto en evidencia el intrincado asunto de la autoficción, veamos, por un lado, el panorama teórico, con sus principales definiciones, para entrar luego en materia con la obra de Sábato. En primer lugar, el análisis de las manifestaciones autoficcionales ha sido un objeto de estudio polémico que se ha desarrollado paulatinamente desde hace cuatro décadas. Este fenómeno fue advertido por Philippe Lejeune a partir de la publicación de El pacto autobiográfico (1975). Sin embargo, tal como lo señala Manuel Alberca, el término es conceptualizado por Serge Doubrovsky (1977), a quien seguirán Vincent Colonna (1989), Jacques Lecarme (1994) y Philippe Vilain. (2005).

Según Doubrovsky, la autoficción es una de las formas innovadoras de la escritura autobiográfica, razón por la cual la mayor parte de los estudios teóricos sobre el tema giran en torno a esta perspectiva. Es en este sentido que Vincent Colonna (1989) retoma la coincidencia de la identidad nominal de la autobiografía y define la autoficción como "una obra literaria en la que el autor se inventa una personalidad y una existencia, conservando su identidad personal, bajo su verdadero nombre" (Alberca, 2006: 8). A

1. Se destaca principalmente el texto de la autora La autoficción en los estudios hispánicos, en el cual se realiza un recorrido sobre el estudio de la autoficción en España y Latinoamérica, resaltando incluso de qué manera han incrementado la difusión científica del tema, especialmente con la celebración de congresos internacionales.

2. Destacando en el terreno de los estudios autobiográficos el Centro de Investigación de Semiótica Literaria, Teatral y Nuevas Tecnologías, en España, dirigido por el Dr. José Romera Castillo, como puede verse en "La escritura (auto)biográfica y el SELITEN@T: guía bibliográfica" (Romera Castillo, 2010). 
partir de esto, Colonna distingue tres funciones en la autoficción:

a) "referencial-biográfica", en la que lo imaginario es reducido al máximo por una voluntad de expresar la verdad [...] b) "reflexivo-especular" o metalepsis discursiva del autor en un relato de ficción con fines paródicos, humorísticos o megalómanos. Por ejemplo, cuando el personaje Andrés Pérez de Niebla viaja a Salamanca para visitar y discutir su suerte con Unamuno, autor de la novela, que de esta manera irrumpe con su propia identidad nominal en la historia de la misma. [...] y c) "figurativa o fantástica”, que es a la que da más importancia y la que mejor cuadra con la definición general de autoficción que elabora Vincent Colonna (Alberca, 2006: 8).

Por otra parte, tomando como punto de referencia a los teóricos mencionados, Manuel Alberca ${ }^{3}$ realiza un breve panorama de las cuestiones problemáticas que se plantean al hablar de los límites de la autoficción. Para ello retoma las nociones del pacto novelesco y pacto autobiográfico, en un afán por aclarar el carácter híbrido de esta reciente forma narrativa. Se pregunta, en primera instancia, si la autoficción se desprende de las formas narrativas autobiográficas o es acaso una subversión de las formas de la novela. Como es de notar por la denominación de su concepto, el pacto ambiguo, el autor concluye que la autoficción en algunas manifestaciones tiende a estar más ligada a la autobiografía, otras veces a la novela y, por último, puede encontrarse en un punto medio (que éste denomina centro autoficcional).

Sin embargo, el asunto se complica más cuando se trata de definir la autoficción como un sub-género de la autobiografía, pues incluso esta se ha puesto en tela de juicio para ser considerada como un género literario (Paul de Man, 1991). En este punto la argumentación de la investigadora argentina Leonor Arfuch es imprescindible. El espacio biográfico, según

3. El artículo de Manuel Alberca de 2006 es una muestra de lo que más adelante desarrollará en su libro El pacto ambiguo. De la novela autobiográfica a la autoficción (2007), en el cual desarrolla de manera más profunda su concepto de pacto ambiguo, el cual aplica a casos de obras de escritores latinoamericanos como César Aira, Fernando Vallejo y Mario Vargas Llosa, sin dejar de lado, por supuesto, a escritores españoles como Javier Marías y Enrique Vila-Matas. 
Arfuch, es "un horizonte de inteligibilidad y no una mera sumatoria de géneros ya conformados en otro lugar" ([2002] 2007: 18), es decir, un espacio donde la heterogeneidad e hibridación de la expresión del "yo" tiene múltiples manifestaciones que no se pueden encasillar. Aunque Arfuch no profundice en la autoficción, su análisis descubre una nueva perspectiva para analizar este fenómeno.

Es en dicho espacio biográfico, como se verá más adelante, que se pretende analizar la obra de Sábato. Desde que se empieza a leer Abaddón se descubre algo inquietante: el narrador cuenta cómo Bruno, un personaje de Sobre héroes y tumbas, ve a Sábato cruzar la calle, absorto en sus pensamientos. Pero, un momento, ¿no es Bruno un personaje de Sábato? Efectivamente. Por lo tanto, el hecho de encontrar al propio autor conviviendo con sus personajes en la ficción nos habla de una ruptura en las formas convencionales de la novela. Es decir, Sábato no se propone escribir su autobiografía, tampoco pretende hacer una novela: realiza un hibrido entre ambas que, como he tratado de mostrar, se puede denominar autoficción.

Ya mencioné que no basta con rastrear aspectos autobiográficos del autor en sus obras para identificar si nos encontramos frente a una autoficción. Aunque sea importante la identidad nominal, que juega un papel clave en este análisis, tampoco es suficiente, ya que en la autoficción se ponen en juego la creación de otras identidades que no corresponden a ese tipo de identidad. Es por esto que pretendo descubrir qué implicaciones tiene la autoficción como estrategia narrativa en la obra de Sábato. Tenemos entonces a un narrador extradiegético que nos presenta a los personajes, aunque estos en ocasiones sean los que narran capítulos íntegros. De modo que no encontramos de entrada la voz del autor y sus vivencias. Entonces ¿Cómo descubrir qué implicaciones tiene, en la narración autoficcional, la disyunción entre autor/narrador/personaje?

Esta pregunta va de la mano con el entramado metaficcional, porque Abaddón es también una ficción que habla sobre sí misma, procura dar cuenta del alcance del autor al decidir construir su obra con todo este entramado narrativo. Sin embargo, para llegar a esto se presentan otras cuestiones que deben resolverse antes. Por ejemplo, ¿en qué modalidad de la autoficción se encuentra la obra? ¿Por qué Sábato recurre al narrador extradiegético para contar los hechos de su vida? ¿Qué simboliza dicha fisura entre autor/narrador/personaje? 
Todas estas cuestiones surgen de esa voluntad de ficcionalizar la propia vida. Por lo tanto, es evidente que la figura del autor - tan difusa al parecer en esta contemporaneidad- juega un papel importante para el análisis de la autoficción en la narrativa de Sábato. A esto se suman los debates de Roland Barthes (1968) y Michel Foucault (1969), que desataron la discusión contemporánea entorno a la muerte del autor, lo que demuestra la relevancia de la autoficción para esta querella, pues el hecho de revivir al autor (muerto) en la obra de arte ¿no evidencia un cuestionamiento de dicha teoría?

\section{FIGURACIONES Y DESFIGURACIONES: CONFORMA- CIÓN DEL ESPACIO BIOGRÁFICO}

Para entrar en materia, es necesario saber que, según Ernesto Sábato, el escritor solo puede revelar sus "(tremendas) 'verdades últimas' mediante la ficción" (1964: 126). Si se hace un balance ligero de la obra ficcional de este autor, en comparación con su escritura no-ficcional, vemos que solamente El túnel, Sobre héroes y tumbas y Abaddón, el Exterminador, pueden revelar estas "verdades" por ser sus únicas obras de ficción. Sin embargo, en la obra no-ficcional de Sábato hay una reiterada voluntad autobiográfica que termina por complejizarse en sus ficciones.

Por lo tanto, dichas "verdades últimas" corresponden a la más íntima expresión de la subjetividad del autor. Esto se revela en el proceso escritural que desemboca en la inclusión de sí mismo como personaje en Abaddón. En esta obra, la voluntad de autorrepresentación pone en juego sus verdades $-\mathrm{y}$ su vida- desde la ficción. Es acá donde se desdibuja la brecha entre lo biográfico y lo ficcional, ya que en la ficcionalización de su propio "yo" Sábato legitima sus pensamientos más profundos, esos que escapan a la superficialidad de la comunicación convencional, para entablar una verdadera expresión de su intimidad con sus lectores.

Teniendo en cuenta lo anterior, quiero mostrar el proceso por el cual Sábato llega al discurso autoficcional. En primer lugar, lo que se puede rastrear sobre la vida de Ernesto Sábato, que no es poco, indica a grandes rasgos sucesos determinantes relacionados con la construcción de una identidad subjetiva. Sé que para muchos estos sucesos son archiconocidos; sin embargo, me interesa reiterarlos porque cumplen una función fundamental en la conformación de su espacio biográfico y, por 
consiguiente, del discurso autobiográfico plasmado en sus ensayos y el discurso autoficcional de sus novelas.

Antes de enumerar estos sucesos, quiero resaltar la importancia del concepto de espacio biográfico, que, como ya he mencionado, proviene de Leonor Arfuch. Para ella lo (auto) biográfico, más allá de estar instaurado como un género discursivo canónico - tal como lo asume Lejeune-, es "un síntoma, aquello que insiste aquí y allí, en el lugar más obvio del discurso y en el menos esperado" (Arfuch, 2007: 49); es decir, un fenómeno que trasciende las formas herméticas y revela un clima de época en el cual "hay un indudable retorno al autor, que incluye no sólo un ansia de detalles de su vida sino de la 'trastienda' de su creación" (51). Teniendo en cuenta esto, volvamos al caso particular de la inserción de Ernesto Sábato en este espacio.

El primero de los sucesos que marca un punto clave en el horizonte biográfico de Sábato, está relacionado con su nombre, Ernesto, el cual, para desgracia del escritor, fue heredado de su hermano, que había muerto poco antes de su nacimiento. El segundo, tiene que ver con su mudanza del pueblo de su infancia, Santos Lugares, a La Plata, donde cursaría estudios secundarios. El tercero, es su incursión en la ciencia. El cuarto, sus visitas a París, primero huyendo de las filas comunistas y luego recluyéndose en el laboratorio Curie ${ }^{4}$ Y el quinto y último, su famosísima decisión de abandonar la ciencia. Después de esto, los grandes cambios se presentarán en su escritura.

Señalo estos sucesos por su carácter esencial en las figuraciones y desfiguraciones ${ }^{5}$ de la identidad del autor, asumiendo éstas como "la restauración de la vida mortal por medio de la autobiografía", la cual "desposee y desfigura en la misma medida en que restaura" (De Man, 1991: 118). Las nociones de figuración y desfiguración de Paul de Man, en este punto, entran a jugar un papel determinante. Para este autor, hablar de autobiografía supone una cuestión paradójica, pues ésta, al ser en apariencia la forma más ajustada a la referencialidad de una vida, es en realidad un resultado de escritura. Con esto, el autor evidencia que la narración de la vida no replica al modelo, sino que lo "engendra", es decir, en la autobiografía la vida es producto de la narración. Esto supone, como en la

4. Para ampliar estas referencias, remito a la tesis doctoral de Julia Érika Negrete Sandoval sobre Abaddón, el Exterminador, donde la autora realiza un detallado panorama de lo que he sintetizado acá.

5. Para estas nociones remito al artículo de Paul de Man, "La autobiografía como desfiguración". 
argumentación de Arfuch, un problema en la distinción entre autobiografía y ficción, el cual, como he tratado de mostrar, podría encontrar un punto de conciliación en esa voluntad que subyace en el discurso autoficcional.

Sin embargo, en la argumentación de De Man el problema de esta distinción es resuelto al negar la categoría de género a la autobiografía, para ser "una figura de lectura y de entendimiento que se da, hasta cierto punto, en todo texto" (114). Sin embargo para el autor también esto tiene su réplica, pues la dificultad de definición genérica revela una inestabilidad que desarticula cualquier delimitación. Por lo tanto, el interés de la autobiografía radica, para éste, no en el conocimiento veraz de una vida, sino en las estrategias de autorrepresentación donde, más que una restitución, hay una desfiguración de la vida que da lugar a una construcción narrativa de la identidad.

Afirmar lo anterior implica, por lo tanto, que detrás de toda construcción narrativa (auto)biográfica subyace un carácter ficcional -el cual se encuentra en la escritura autoficcional como voluntad-. De esta manera se podría pensar que el discurso autoficcional es inherente a todo proceso de escritura autorreferencial. Sin embargo, aún tenemos arraigada esa persistencia que nos impulsa a firma un pacto, en el cual aceptamos la creencia de una narración de la "vida real", cuya garantía imprime el autor en su discurso, lo cual remite, como señala Arfuch, a otro horizonte de expectativa.

Como se puede observar, Sábato ingresa al mundo de la razón y la objetividad, en una primera etapa de su vida (hasta 1938), por medio de la ciencia. Luego de esto empezará a construir, empezando con Uno y el universo (1945), las bases de una expresión subjetiva lejos de los mecanismos de la ciencia, que desembocará en la inclusión de sí mismo en la ficción. No obstante, me interesa detenerme en ese proceso porque arroja una luz sobre la dificultad de Sábato para entregarse por completo a las ficciones.

Si el abandono de la ciencia supone una figuración de su identidad, la decisión de publicar su ópera prima -es decir, su entrada en el mundo de la ficción- implica una desfiguración que tendrá repercusiones tanto en la conformación de su espacio biográfico como en los procesos de subjetivación en la escritura latinoamericana. Con esto me refiero a El túnel, publicado en 1948, donde el autor implementa la narración autodigética y la exploración de la consciencia del personaje como una forma innovadora 
de escritura, con raras excepciones que se le comparan, como el Adán Buenosayres (1948) de Leopoldo Marechal. Después de El túnel, pasarán trece años sin que el autor se atreva a publicar otra ficción. Mientras se dedica a la piromanía, ese impulso kafkiano que lo insta a quemar por la tarde lo que había escrito en la mañana.

Sin embargo, en materia de ensayo, publicará, antes de su novela Sobre héroes y tumbas (1961), Hombres y engranajes (1951) y Heterodoxia (1953), textos en los cuales expondrá sus ideas más arraigadas sobre el arte, la novela, la vida y el papel del escritor en el mundo. Luego pasarán otros trece años para que Sábato se decida a publicar su última ficción. Por lo pronto, la aparición de Sobre héroes y tumbas (1961), a pesar de confirmar su posición en las letras hispanoamericanas, deja entrever los primeros mecanismos que servirán para la conformación del espacio biográfico, tales como la autorreferencialidad, que se presenta de manera indirecta, y la metaficción (con sus implicaciones: intertextualidad, hipertextualidad, metatextualidad, etc.).

No obstante, con la publicación de El escritor y sus fantasmas (1963), Sábato seguirá al margen -por lo menos implícitamente- de sus ficciones. Es decir, si asumimos los ensayos de Sábato como muestras de una identidad autobiográfica muy temprana, nos encontramos, siguiendo a Puertas Moya, en el ámbito del byos y el graphé, es decir, "en la escritura (...) [de] los hechos y acontecimientos de su vida que [el escritor] selecciona para su exposición y explicación" (2003: 41), puesto que el autos, ese descubrimiento del "yo" mediante la escritura, aún requerirá de una voluntad autorreferencial.

Ahora bien, realizado este breve recorrido que va desde el abandono de la ciencia como un primer momento de subjetivación, hasta el momento que he indicado, queda claro hacia dónde se dirige Sábato. Evidentemente, hay una progresión consciente que cimenta, con cada obra, los pilares de una subjetivación escritural y, al mismo tiempo, de un imaginario construido del "yo" autorial. Es así cómo el sujeto público, que ha mostrado desde un único ámbito su intimidad de escritor, llega a la hibridación entre lo público y lo privado por medio de la ficción. Este es el caso de Abaddón, El Exterminador (1974).

Puesta en evidencia la distancia temporal que separa las únicas obras de ficción de Sábato, no cabe duda de que el proceso de reflexión sobre el quehacer del escritor alcanza su máxima expresión en la última obra, pues 
los mecanismos que se despliegan en ella, tales como la autoficción y la metaficcionalidad, son pruebas de la autoconciencia que tiene el autor sobre la escritura y, más precisamente, sobre la novela. De esta manera Sábato conforma su espacio biográfico con la escritura de Abaddón, volviéndose personaje de su mundo ficcional y creando un discurso autoficcional que determina, previamente a sus memorias Antes del fin (1998), ese autos que complementa la expresión de las vivencias de un "yo" mediante la escritura.

\section{EL DISCURSO AUTOFICCIONAL}

-No hablo de un escritor dentro de la ficción. Hablo de la posibilidad extrema que sea el escritor de la novela el que esté dentro.

Pero no como un observador, como un cronista, como un testigo.

\section{Abaddón, El Exterminador Ernesto Sábato}

Antes de observar el discurso autoficcional, quiero hacer énfasis en esa presencia implícita del autor en sus ficciones, partiendo de lo que Philipe Lejeune denominó pacto fantasmático, el cual, según Alicia Molero, consiste "en todas aquellas novelas donde, sin que el personaje remita expresamente al autor, el lector reconozca en él los atributos o circunstancias de quien firma la obra" (Molero, 2000: 536). Esto es lo que sucede con El túnel y Sobre héroes y tumbas: tanto Juan Pablo Castel, que es pintor como el mismo Sábato, al igual que Bruno, que es un escritor frustrado, representan en cierto grado aspectos de esa identidad del autor con sus personajes -identidad que Sábato siempre ha reiterado-. Así, estos primeros impulsos implícitos empiezan a romper la brecha que separa la ficción de la propia vida, dando lugar a esas relaciones fantasmáticas que se desprenden de la vida pública del autor (entrevistas y ensayos donde se resalta su opinión) y se configuran en la autoficción y sus memorias.

Ahora bien, la conciencia que tiene el autor de explorar el mundo no como algo irreconocible (tal como lo hace Cervantes con su don Quijote) sino como una creación desde la propia subjetividad, es el punto clave del discurso autoficcional. Es en este sentido que se dirige Sábato con 
su Abaddón. Al ser consciente de no poder comunicarse con el mundo, experimenta con crear una obra en la que trascienda las barreras de la objetividad, ese mundo real que no puede alcanzar sino ficcionalizando su propio "yo". Con esto, la idea de la muerte del autor, planteada por Roland Barthes y Michel de Foucault, se pone en cuestión en la misma práctica de ficcionalizar:

Stephen Dedalus, en el Retrato, nos dice que "la personalidad del artista es a primera vista grito y cadencia, y después narración fluida y ondulante, desaparece de puro refinamiento, se impersonaliza, por decirlo así... El artista, como el Dios de la creación, queda dentro, o más allá, o por encima de su obra, invisible, sutilizando fuera de la vida, indiferente, arreglándose las uñas". La novela debía ser una épica moderna, y como toda épica exigiría la desaparición total del narrador. iQué ilusión! Por lo que sabemos de la vida de Joyce, tanto el Retrato como el Ulises no son sino la proyección sentimental, ideológica y metafísica del propio Joyce, de sus propias pasiones, de su drama o tragicomedia personal (Sábato, 1964: 154).

Si se tiene en cuenta lo anterior, dicha invisibilidad del autor es debatida, más allá de la obra de Sábato, por la misma voluntad de los escritores contemporáneos por confundir su vida con la ficción. Es decir: la autoficción sería entonces un mecanismo de subjetivación e intimismo cuya función principal es desfigurar la figura del autor para reivindicarla.

Por otra parte, cabe preguntarse: ¿se puede crear la identidad del "yo" a través de la escritura? Ciertamente dicha identidad sería esencialmente narrativa. Sin embargo, la brecha entre lo real y lo ficcional de ese "yo" no es tan simple como para analizarla desde una u otra perspectiva. Por esta razón, la creación autoficcional, vista como esa voluntad que desfigura la vida a través del arte, crea un punto de negociación entre ambas partes, pues ya no debemos apelar a un pacto novelesco o autobiográfico sino a su hibridación: el pacto ambiguo, donde la disolución entre lo privado y lo público, como entre lo real y lo ficcional, viene a dar cuenta de una nueva concepción del sujeto en la escritura contemporánea.

Esto implica necesariamente que Sábato, al reconstruir a partir de 
sucesos determinantes las situaciones, sentimientos y hechos de su vida, se observe, tal como apuntó Paul Ricoeur, a sí mismo como otro y por lo tanto emprenda la diferenciación entre su identidad sustancial y la identidad narrativa que establece con Sábato- personaje ${ }^{6}$. Todo esto se dirige, como también plantea Sábato en sus ensayos, a la reivindicación del autor como parte fundamental en la construcción de la obra y al análisis imprescindible del proceso (en nuestro caso autoficcional) mediante el cual un autor emprende una obra en la que están en juego sus vivencias:

Consideremos un árbol. Primero lo pinta Millet y luego lo pinta Van Gogh. Resultan dos árboles distintos, en virtud de esa "maldita intervención del autor". Pero es precisamente esa (inevitable) irrupción del artista en el objeto lo que hace superior el árbol de Van Gogh al árbol de Millet y al de cualquier fotógrafo. Más, todavía: ese árbol es el retrato del alma de Van Gogh (Sábato, 1964: 124).

Por supuesto, en dicho análisis de las diversas identidades del autor que se despliegan en Abaddón, no podemos excluir, como he tratado de reiterar, el papel que juega el lector en esta reconstrucción. Lejos de las ideas de Roland Barthes, para quien "el nacimiento del lector se paga con la muerte del autor" (2009: 71), me interesa resaltar la intención integradora e intersubjetiva de Sábato, para quien "el Tú (contemplador) alcanza al Yo (artista) a través del objeto artístico y no en el objeto artístico. Como lector de Rojo y negro yo ingreso en la intimidad misma de Stendhal, y él ingresa en la mía como creador" (1964: 157).

En este sentido podemos ver cómo Sábato no sólo intenta entenderse a sí mismo y a sus ficciones, sino también la ruptura que éste desea generar con respecto a la objetividad extrema donde, en últimas, ni siquiera el lector tendría importancia porque sólo interesaría el hecho discursivo.

\section{LA METAFICCIÓN}

6. Esta distinción es explicada por Leonor Arfuch de la siguiente manera: “QQuién habla en la instancia actual del relato? [...] ¿quién es el sujeto de la historia? Para Ricoeur el dilema se resuelve, como anticipábamos, con la sustitución de un 'mismo' (idem) por un 'sí mimo' (ipse); siendo la diferencia entre idem e ipse la que existe entre una identidad sustancial o formal y la identidad narrativa, sujeta al juego reflexivo, al devenir de la peripecia, abierta al cambio, la mutabilidad, pero sin perder de vista la cohesión de una vida" (Arfuch, 2007: 90). 
El hecho de estar ante una obra cuyo tema es la escritura de sí misma, deja claro un procedimiento narrativo que se denomina metaficción. Éste, que ha surgido casi al mismo tiempo que la novela y podemos rastrear incluso en Don Quijote, es un recurso que utiliza el escritor de ficciones para pensar y cuestionar el mismo acto de escritura. Por lo tanto, la autoconciencia y la metacognición (el hecho de pensar sobre lo que se piensa y hace) están estrechamente ligadas al acto mismo de escribir una ficción que trata sobre la ficción.

Todo esto, más allá de ese juego de palabras a la segunda potencia, advierte esa exploración del escritor consciente de su subjetividad que aparece con la novela moderna. Desde la célebre frase "conócete a ti mismo", grabada en el templo de Apolo en Delfos, o el "yo pienso" cartesiano, podemos ver cómo la Modernidad hizo gala de su novedoso descubrimiento: el sujeto, del cual su principal atributo es la autoconciencia. Sin embargo, como no nos enfrentamos a una novela "moderna" en el sentido estricto de la palabra, hay que aclarar que la exploración de Sábato se dirige a reflexionar y evaluar la idea misma de sujeto. De modo que el simple hecho de saberse sujeto ya no basta, pues el optimismo que estimulaba al sujeto moderno ya no ofrece ninguna garantía: su autoconciencia ha quedado cegada por su narcicismo.

Para ejemplificar de qué manera se manifiesta la metaficción en Abaddón, El Exterminador ${ }^{7}$, quiero traer la siguiente cita, extraída de un reportaje ficticio que aparece en la novela de Sábato:

-Está satisfecho con lo que ha escrito?

-No soy tan canalla.

-Quién es Ernesto Sabato?

- Mis libros han sido un intento de responder a esa pregunta. Yo no quiero obligarlo a leerlos, pero si quiere conocer la respuesta tendrá que hacerlo.

- Puede adelantarnos la primicia de lo que está escribiendo en estos momentos?

-Una novela.

7. Para observar la complejidad de la metaficción en la obra de Sábato, que va más allá de las intenciones planteadas acá, remito al artículo de Myrna Solotorevsky (2010), "Especularidad y narcisismo en Abaddón, El Exterminador". 
-Tiene ya título?

- Generalmente lo sé al final, cuando terminé de escribir el libro. Por el momento tengo dudas. Puede ser EL ÁNGEL DE LAS TINIEBLAS. Pero quizá ABADDÓN, EL EXTERMINADOR (1983: 223).

En lo anterior no solo se evidencia la voz del autor en su propio discurso autoficcional, sino que aparece una referencia al mismo libro que leemos. He mencionado que Sábato, desde la construcción de su identidad, llega a una desfiguración por medio de la autoficción. Si observamos la metaficción desde este punto de vista, vemos cómo ésta sirve al autor para descubrir lo que implica ser un personaje de su novela, pues se confirma, con el escritor abriendo las puertas de su taller, lo que de modo sarcástico el personaje Quique nos menciona en Abaddón, donde la autoconciencia, las alusiones al acto de producción de la novela y los comentarios críticos y literarios (entre los cuales se encuentran las Ideas de Quique sobre la nueva novela) están destinados a "hacer participar al lector, porque como se sabe, antes el lector no participaba, se limitaba a leer como un poste de quebracho, o como un tótem, o como un adoquín" (Sábato, 1983: 198).

Todas las ideas que se reiteran a lo largo de la novela, las reflexiones sobre el arte, la ciencia, la literatura; los antecedentes de la gestación de las novelas anteriores; la búsqueda de un impulso que dé forma a la obra que Sábato desea escribir, desembocan en la metaficción como una forma de autoconciencia que impulsa al autor a conciliar la extrema objetividad del positivismo con una búsqueda subjetiva mediante el arte, cuyo objetivo es realizar, en palabras del mismo Sábato, la síntesis del ser humano escindido por la razón científica.

Si nos preguntamos ¿qué significa desfigurar la propia existencia en la escritura? la mejor forma de responder a esto es apelando al papel que tiene la autorreferencialidad y la metaficción en una obra autoficcional. Para el primer caso, es evidente que consiste en tratar de descubrir y dotar de significado la existencia por medio del arte. En lo que concierne a la metaficción, me interesa mostrar la opinión de Julia Érika Negrete Sandoval. Para ella:

Abbadón es una novela sobre la dificultad de escribir una novela, que es la misma Abbadón. La crisis del escritor 
que se anuncia al principio, no es otra que la que enfrenta Sábato personaje en proceso de escritura de un libro al que posiblemente pondrá como título "Abbadón, El Exterminador". Son varios los momentos que rodean esta crisis: desde la reunión espiritista donde se trata de saber qué o quién es la entidad que impide a Sábato escribir, los antecedentes que el personaje da a conocer en una retrospectiva de su vida narrada en primera persona, hasta las menciones explícitas sobre la condición específica del acto creativo (Negrete Sandoval, 2013: 171-172).

A partir de lo anterior, queda claro que la metaficción no sólo sirve al entramado narrativo que da razón de ser a la novela, sino que es desde ésta desde la que Sábato anuncia su crisis y al mismo tiempo la explora. Así, me arriesgo a pensar que la autoficción, más allá de ser una búsqueda por configurar una identidad factual, es una desfiguración de la propia existencia en un afán por dotar de sentido la expresión subjetiva que quiere comunicar el autor a sus lectores. Por lo tanto, ser personaje de su propia novela implica que un autor desfigure su existencia para ser juez y al mismo tiempo constructor de una identidad narrativa de la propia vida.

\section{SÁBATO FUERA DE SÍ: UNA RUPTURA DEL DISCURSO AUTOFICCIONAL}

Una de las cuestiones más importantes a la hora de explorar las estrategias narrativas que Sábato utiliza para recrearse como un personaje en la ficción, tiene que ver con la ruptura que hay entre autor/ narrador/ personaje. Esta ruptura, dada por un narrador extradiegético que no revela su identidad, y al cual le es arrebatada la narración en diversas ocasiones por Sábato-personaje, puede tomarse como un recurso del autor para evitar algunas implicaciones problemáticas que la narración autodiegética trae consigo. Así, el lector podría pensar que la distancia que crea el autor con su personaje da una objetividad y un carácter más verídico a lo narrado. Sin embargo, esta ruptura, como veremos, lejos de estar del lado de la ficción o la realidad, tiene como objetivo conciliar esta antigua oposición.

Nada extraño resulta, dadas las conocidas intenciones del autor al tratar de dirigir su trabajo en esa búsqueda del absoluto, que en su última 
ficción Sábato transgreda todos los esquemas que la lógica binaria postula, para abordar la exploración de su 'yo' en su carácter complejo y múltiple y no en la simple división 'yo'/ 'los otros', pues todo apunta en esta contemporaneidad a evidenciar el 'yo' como un concepto múltiple que se desdobla para observarse a sí mismo mediante la reconstrucción del pasado. Esta mutabilidad es ejemplificada por Francisco Puertas Moya con la siguiente metáfora:

Dos movimientos se pueden apreciar en la sustancia individual: el de traslación y del de rotación, a semejanza del planeta que habitamos. Por el movimiento de traslación, el yo evoluciona y se mueve, cambia y se transforma, aunque simultáneamente el yo rota en torno a sí mismo para asegurar la identidad, la permanencia y la continuidad, se observa a sí mismo y se considera centro de todas sus expectativas (Puertas Moya, 2003: 112).

Por lo tanto, consciente de su 'traslación', Sábato no desconoce que el 'yo' narrado no corresponde a su 'yo' presente de autor-creador, razón por la cual interpone a un narrador que medie entre ambos, sin que la 'rotación' sobre sí mismo se pierda completamente desvaneciendo su identidad. Para Sábato:

La filosofía por sí misma es incapaz de realizar la síntesis del hombre disgregado: a lo más puede entenderla y recomendarla. Pero por su misma esencia conceptual no puede sino recomendar conceptualmente la rebelión contra el concepto mismo, de modo que hasta el propio existencialismo resulta una suerte de paradójico racionalismo. La auténtica rebelión y la verdadera síntesis no podía provenir sino de aquella actividad del espíritu que nunca separó lo inseparable: la novela. Que por su misma hibridez, a medio camino entre las ideas y las pasiones, estaba destinada a dar la real integración del hombre escindido; a lo menos en sus más vastas y complejas realizaciones. En estas novelas cumbres se da la síntesis que el existencialismo fenomenológico recomienda. Ni la 
pura objetividad de la ciencia, ni la pura subjetividad de la primera rebelión: la realidad desde un yo, la síntesis entre el yo y el mundo, entre la inconsciencia y la conciencia, entre la sensibilidad y el intelecto (Sábato, 1968: 85-86).

Con estas ideas explícitas del autor, podemos acercarnos a las intenciones que sustentan la estructura híbrida de la obra, la cual se nos escapa al intentar encasillarla como ficción o autobiografía, y que podemos ubicar en esa modalidad de la autoficción que Manuel Alberca denomina centro autoficcional. Para éste, la autoficción puede ubicarse en tres instancias. La primera, denominada periferia A, corresponde a aquellas autoficciones en las que el contenido autobiográfico tiene mayor relevancia que el ficcional. En la segunda, periferia $\mathrm{B}$, adquiere más fuerza el contenido ficcional que el autobiográfico. Por último, tenemos en medio de estas dos periferias el centro autoficcional, que en "la integración de los elementos ficticios y autobiográficos y su carácter indisoluble pueden, a veces, dejar al lector vacilante a la hora de descifrar el estatuto del relato" (Alberca, 2005-2006: 13-14).

Ahora bien, ¿por qué Sábato está fuera de sí? Como he mencionado, la ruptura del narrador entre autor y personaje demuestra de manera tajante que estos no son la misma persona. A diferencia de la autobiografía (donde hay una pretensión por mantener la unidad del 'yo'), en la autoficción se revela el carácter ambiguo y múltiple que puede adquirir la narración de una vida, la cual, por lo demás, no desconoce que la ficción como necesidad antropológica (Wolfgang Iser, 1990) nos ha ayudado a elaborar nuestra concepción del mundo. En este sentido Sábato, al realizar una ruptura entre él y su personaje, lleva a los extremos la multiplicación de su 'yo' a la manera de una muñeca rusa.

Este juego, que reduplica la perspectiva del novelista (como autor y personaje[s] que se desdoblan) con respecto al referente (la relación con el mundo factual), es el que da lugar al intento de Sábato por integrar todo en una búsqueda de lo 'absoluto', lo 'total'. Al igual que la estructura rizomática ${ }^{8}$ de la novela, el ‘yo’ de Sábato se ramifica -incluso llega a

8. La noción de rizoma, extraída de la botánica y replanteada por Gilles Deleuze y Félix Guattari (1972) en la introducción de Mil Mesetas. Capitalismo y esquizofrenia, consiste en una estructuración del pensamiento caracterizada por su tendencia hacia la multiplicidad, la apertura, el caos, la complejidad, lo paradójico, lo inacabado. Partiendo de esto, Julia Erika Negrete Sandoval analiza la estructura de Abaddón, pues al leer 
metamorfosearse en murciélago- para tratar de relacionar las categorías Mundo/ Texto/ Yo en una interacción que pueda comunicar lo más esencial de su subjetividad a los lectores. Como ya he mencionado, esta hipótesis evidencia una tentativa del autor por alcanzar, como con la 'novela total', esa conciliación del 'yo' (subjetivo) con el mundo (objetivo).

Sin embargo, una idea que ronda a partir de 1968, promulgada por Roland Barthes y, casi inmediatamente, retomada por Michel Foucault (1969), nos dice que el autor, al llevar a cabo el acto de escritura, se instala en un lugar neutro donde el sujeto pierde su identidad. De esta manera nos dicen "iqué importa quién habla!", con lo cual el intento de Sábato no tendría ningún tipo de validez. Sin embargo, en ese gran cementerio de autores podemos escuchar murmullos milenarios que claman por comunicarse. Por lo tanto, la autoficción, que se ocupa de estos fantasmas, arroja una nueva perspectiva del asunto "en tanto tendencia principal de la reivindicación autoral" (Negrete Sandoval, 2013: 62).

En este sentido, las ideas de Sábato, aun cuando no sea de manera explícita, entran a cuestionar las polémicas en torno a la muerte del autor al reivindicar su figura como autor-personaje, con lo cual el carácter autorreferencial de la obra, los desdoblamientos y fantasmas, nos advierten de esa unidad primera que es la síntesis del hombre escindido que Sábato siempre ambicionó.

\section{RETROSPECCIÓN Y MEMORIA COMO MECANISMOS AUTOFICCIONALES}

He hablado de fantasmas en relación con Abaddón, El Exterminador en términos de la autoficción. Al hacerlo tengo la intención de señalar, por un lado, el carácter etéreo de los personajes autoficticios (que no por esto dejan de existir y estar ligados al autor) y, por el otro, que éstos dependen de dos mecanismos básicos en la reconstrucción del pasado autobiográfico: la retrospección y la memoria, los cuales producen y contienen el material que utiliza Sábato para reconstruir su vida y reevaluarla en su universo ficcional.

Por lo tanto, creo necesario observar con detalle los procesos

esta obra nos damos cuenta que las estructuras lineales y convencionales de las novelas, en las cuales podemos rastrear algún tipo de temporalidad, no se pueden aplicar para su análisis. 
que están en juego a la hora de utilizar la retrospección y la memoria como mecanismos fundamentales en el discurso autobiográfico que se reconstruye y mezcla con la ficción. Para ello, me interesa acudir una vez más a Francisco Puertas Moya, quien nos explica cómo se utilizan éstas en función de la escritura autobiográfica. Primero, es necesario saber que la retrospección es una actividad que nos lleva indagar el pasado en función de una determinada situación presente.

De esta manera, quien se dispone a realizar un relato con tintes autobiográficos (como sucede en la autoficción), tendrá primero que realizar esta indagación que lo llevará a racionalizar y concientizar las acciones de ese otro 'yo' que ha actuado casi que de manera inconsciente e irreflexiva en el pasado. Esta vuelta a sí mismo como otro será el primer distanciamiento necesario para emprender la escritura en tanto la mirada retrospectiva es un rasgo común de la escritura autobiográfica, pues sólo por medio del pasado es posible comprender la raíz de los comportamientos y la forma de ser de quién se busca en él mismo. Por lo tanto, "escribir sobre la propia vida exige reconstruirla textualmente, intentando ser fiel a lo que sucedió en el pasado, remontándose a contracorriente en el flujo de la existencia" (Puertas Moya, 2003: 52).

En consecuencia, la retrospección implica realizar una introspección en la cual están en juego la interpretación y explicación de sucesos inconexos en la memoria, a muchos de los cuales (tal como puede suceder a cualquiera que se cuestione por qué ha llegado a determinada situación) el autor otorga relaciones de causalidad para descifrar el acontecimiento que trata de explicar. En este acto, es importante tener en cuenta la temporalidad y la ordenación cronológica de los sucesos narrados. Sin embargo, en Abaddón, aun cuando podamos reconocer cierta cronología subyacente, la estructura rizomática se encarga de emborronarla cuando creemos que la hemos comprendido.

Como es de esperar por el carácter autoconsciente de Sábato en Abaddón, el hecho de no poder hablar de un tiempo lineal se debe a que en la obra, desde su estructura, el autor no intenta organizar los hechos, sino que trata de mostrarlos tal y como se presentan en la memoria, es decir, con sus fallos y olvidos que lo obligan a reconstruir versiones artificiales de los hechos. Así, según Puertas Moya, la escritura autobiográfica sería como una segunda piel, una reinvención que disfraza lo que fue un momento, cuya reconstrucción es una artificialidad plagada de engaños, errores, 
imposturas y trampas, pues "sobreponer a la conciencia del pasado la nueva consciencia de la escritura aporta una específica perspectiva dual que impregna y caracteriza al género autobiográfico, en el que el presente dota de sentido al pasado y reorganiza o reinterpreta el significado de la vida" (55).

Por supuesto, en la escritura autoficcional este carácter de artificio se presenta sin ambages, pues, como ya he mencionado, la voluntad del autor al utilizar su 'yo' para el juego reflexivo y la mutabilidad que implica la ficción no pretende en ningún momento evadir estas cuestiones. De hecho la memoria, que es el sistema en el cual se encuentran articulados todos los recuerdos, es utilizada por Sábato como base fundamental para escuchar su propia voz. De este modo se genera la consciencia de la unidad y la variabilidad del ser, ya que la distancia temporal que implica el recuerdo traza un hilo de continuidad que relaciona su 'yo' presente (narrador) con su 'yo' pasado (narrado).

Ahora bien, en lo que respecta a la memoria, varias son las cuestiones que se presentan en relación con la construcción de la identidad. Por un lado, tenemos que la memoria es un proceso flexible, maleable y manipulable, de modo que no podemos señalar a ésta como depositaria de un pasado inalterable que será reconstruido tal cual ha sucedido. Por otra parte, cabe apuntar que la memoria depende de múltiples factores que van desde la función sociocultural, la cual interviene en nuestra manera de ver el mundo inscritos en una historia y una cultura determinada, hasta la función individual, encargada de crear y diferenciar nuestra identidad subjetiva de otras identidades.

En lo que respecta a la identidad del autor, esta última función de la memoria es la que nos interesa, pues:

El individuo se constituye socialmente gracias a la búsqueda de su propia identidad, de aquello que lo diferencia del resto de la comunidad [...] Abandonarse a la creación de una identidad especifica es la tarea que se asume en todo escrito autobiográfico, por lo que se utiliza la memoria como el hilo conductor que articula y estructura el discurso de esa búsqueda, inscrita a su vez en el marco de unas relaciones sociales y de una comunidad cultural (Puertas Moya, 2003: 60). 
Así vemos cómo Sábato, al aventurarse a relatar sucesos de su vida, se busca a sí mismo para justificar ante él y sus lectores el hecho de escribir ficciones. De este modo, y esto es fundamental para la construcción del discurso autoficcional, el olvido entra a jugar una parte imprescindible en esta justificación debido a que la memoria es la reconstrucción de algo que se encuentra irremediablemente perdido ${ }^{9}$. Por lo tanto, en esta selección y organización pre-narrativa que la memoria ejerce sobre los recuerdos que se reconstruyen, vemos cómo ésta no sólo es manipulable y alterable sino de qué manera utiliza procedimientos ficcionales para dar cuenta de lo que ha sucedido.

En este sentido, me parece muy pertinente la perspectiva que retoma Puertas Moya en relación con este proceso de ficcionalización que lleva a cabo la memoria:

Jugando con la paradoja que supone la ficcionalidad de la reconstrucción rememorativa, Antonio Muñoz Molina ha llegado a señalar que "para ser más veraz, la memoria en ocasiones se convierte en ficción”, por lo que no conviene creer que la extrema fidelidad de la memoria responda a un acto puramente racional, sino que más bien este puede provenir de esa capacidad inventiva y ficcional que activa lo autobiográfico (Puertas Moya, 2003: 71).

Estas ideas coinciden con la necesidad antropológica de la ficción, tal como lo ha planteado Wolfgang Iser, pues "si el yo íntimo de la persona es el punto de encuentro de sus múltiples papeles, las ficciones literarias muestran a los seres humanos como ese algo que ellos se hacen ser y cómo que ellos entienden que son" (Iser, [1990] 1997: 57). De esta manera vemos cómo la autoficción, amparada por la memoria y la retrospección, si bien reconstruye y proyecta múltiples versiones de los sucesos y de la subjetividad del autor, refleja una idea aproximada de la identidad personal de quien narra, pues en el mismo acto de escritura está la voluntad de comprenderse a sí mismo.

9. No obstante, es necesario aclarar que este aspecto no es en absoluto negativo. De hecho es este mismo carácter irremediable el que nos hace volver hacia lo que fuimos, por lo cual la memoria cumpliría una función metacognitiva en tanto nos permite ser conscientes de nuestra consciencia en el espacio y el tiempo. 


\section{COMUNICACIÓN MEDIANTE EL ARTE: LA IMPOR- TANCIA DEL AUTOR EN LA OBRA}

Con todo lo que he planteado hasta ahora, se puede decir que Ernesto Sábato se introduce en la ficción como un personaje más para reivindicar la figura del autor, con lo cual se pone en evidencia la voluntad de los escritores por superar la llamada "muerte del autor", pues el arte sería, de esta manera, la forma de expresión subjetiva del "yo". Es decir, en oposición a la creencia de que una obra sólo comunica su propio mundo y que todo acto de comunicación es una objetivación del "yo", Sábato mezcla su vida con la ficción para mostrar que la obra es la propia vida y es a través de ella donde hay una verdadera comunicación subjetiva con "el otro": el lector que ingresa en la intimidad del autor y deja que este ingrese en la suya.

De esta manera, vemos que la autoficción es un mecanismo que, al trastocar los límites entre la realidad y la ficción, pretende dar cuenta de una nueva expresión de la subjetividad contemporánea. Y no sólo esto. El hecho de que un autor se incluya en su obra demuestra que hay una voluntad por reivindicar su papel en el acto creativo. Por esta razón, tanto la autorreferencialidad, como la metaficción, son una exploración de ese "yo" tan inasible que todo artista contemporáneo busca desenredar. Es decir, la autoficción sería una forma más de esa expresión de la propia vida que busca todo artista, y que, para Gilles Deleuze, no es otra cosa que la vida como obra de arte.

\section{REFERENCIAS BIBLIOGRÁFICAS}

ALBERCA, M. (2005-2006). “¿Existe la autoficción Hispanoamericana?”. Cuadernos del Cilha 11-12 (7-8), 5-17. Recuperado de: http:// bdigital.uncu.edu.ar/objetos_digitales/1095/albercacilha78.pdf [15/02/2017]. (2007). El pacto ambiguo. De la novela autobiográfica a la autoficción. Madrid: Biblioteca Nueva.

ARFUCH, L. (2002). El espacio biográfico: dilemas de la subjetividad 
contemporánea. Buenos Aires: FCE. [2007].

BARTHES, R. (2009). El susurro del lenguaje. Barcelona: Paidós.

CASAS, A. (ed.) (2014). El yo fabulado. Nuevas aproximaciones críticas a la autoficción. Madrid: Iberoamericana-Vervuert.

COLONNA, V. (1989). L'autofiction (essai sur la fictionalisation de soi en Littérature). París: École des Hautes Études en Sciences Sociales.

DE MAN, P. (1991). "La autobiografía como desfiguración". Anthropos. Suplementos 29, 113-118.

FOUCAULT, M. (1999). ¿Qué es un autor? Recuperado de http://www. saber.ula.ve/bitstream/123456789/15927/1/davila-autor.pdf [15/02/2017].

GUATTARIA, F. y DELEUZE, G. (1980). Mil mesetas. Capitalismo y Esquizofrenia. Valencia: Pre-Textos [2002].

ISER, W. (1990). "La ficcionalización: dimensión antropológica de las ficciones literarias". En Teorías de la ficción literaria, A. Garrido Domínguez (ed.), 43-65. Madrid: Arco / Libros [1997].

LEJEUNE, P. (1975). El pacto autobiográfico. Madrid: MegazulEndymión [1994].

MOLERO DE LA IGLESIA, A. (2000). "Autoficción y enunciación autobiográfica". Signa. Revista de la Asociación Española de Semiótica 9, 531-547. Recuperado de http://www.cervantesvirtual. com/obra-visor/signa-revista-de-la-asociacion-espanola-desemiotica--8/html/dcd931cc-2dc6-11e2-b417-000475f5bda5_37. html\#I_59_[15/02/2017].

(2006). "Figuras y significados de la autonovelación". Espéculo. Revista de estudios literarios 33. Recuperado de http://www. biblioteca.org.ar/libros/151313.pdf [15/02/2017].

MUSITANO, J. (2010). “Autoficción: ¿género literario o estrategia de autofiguración?”. Boletín/15. Centro de Estudios de Teoría y Crítica Literaria de la Facultad de Humanidades y Artes de la Universidad Nacional de Rosario. Recuperado de http://www. celarg.org/int/arch_publi/musitano.pdf [10/08/2017].

NEGRETE SANDOVAL, J.E (2013). Autor y autoficción: un estudio de Abaddón, El Exterminador de Ernesto Sábato. Recuperado de http://tesis.colmex.mx/ [15/02/2017].

PUERTAS MOYA, F. E. (2003). La escritura autobiográfica en el siglo XIX: el ciclo novelístico de Pío Cid considerado como 
la autoficción de Ángel Ganivet. Tesis doctoral, dirigida por el prof. José Romera Castillo. Universidad Nacional de Educación a Distancia. Recuperado de http://www.cervantesvirtual.com/ obra/la-escritura-autobiografica-en-el-fin-del-siglo-xix-el-ciclonovelistico-de-pio-cid-considerando-como-la-autoficcion-deangel-ganivet--0/[15/02/2017].

RICOEUR, P. (1988). Historia y narratividad. Barcelona: Ediciones Paidós Ibérica. [1999].

ROMERA CASTILLO, J. (2010). “La escritura (auto) biográfica y el SELITEN@T: guía bibliográfica”. Signa 19, 333-369. Recuperado de http://www.cervantesvirtual.com/obra/la-escritura-autobiografica-y-el-selitent-guia-bibliografica--0/ [15/03/2017].

SÁBATO, E. (1964). El escritor y sus fantasmas. Buenos Aires: Aguilar. (1968). Tres aproximaciones a la literatura de nuestro tiempo. Santiago de Chile: Editorial Universitaria.

(1983). Abaddón, El Exterminador. Bogotá: Oveja Negra.

SOLOTORIEVSKY, M. (1981). "Especularidad y narcisismo en Abaddón, El Exterminador". Anales de Literatura Hispanoamericana, 9 (10). Recuperado de http://revistas.ucm.es/index.php/ALHI/article/viewFile/ALHI8181110295A/24484 [10/08/17].

TORO, V.; SCHLIKERS, S. y LUENGO, A. (eds.) (2010). La obsesión del yo. La auto(r)ficción en la literatura española y latinoamericana. Madrid: Iberoamericana-Vervuert.

Recibido el 26 de mayo de 2017.

Aceptado el 25 de julio de 2017. 